\title{
Analyzing in situ Geothermal EnergyContribution to Hydrocarbon Reservoir Pressure
}

\section{Olafuyi Olalekan* and Ekeregbe MP}

University of Benin, Benin City, Nigeria Department of Environmental Education, University of Calabar, Nigeria

\begin{abstract}
In any closed fluid system there exists a relationship between pressure and temperature. For liquid system, a change in density with a change in temperature impacts on the fluid pressure if the fluid expansion is contained in a rigid system boundary. Geothermal energy in the earth interior has been exploited for different purposes such as heating and power generation. But no influence of geothermal energy on hydrocarbon reservoir fluid in situ in the earth interior has ever been thought of. This pressure contribution to reservoir pressure due to geothermal energy is what this paper seeks to quantify by examining the thermal conductivity of the reservoir fluids- formation system and the reservoir architecture. Because of the complex representation of the different components of the reservoir, the relationship between the pressure and temperature in the reservoir has a complex polynomial relation which depends on changing reservoir parameters. The pressure contributed due to geothermal energy is significant depending on reservoir architecture, fluid and formation properties. A major limiting factor is the reservoir pay zone thickness known as the traverse length.

This paper presents a relationship between temperature and pressure in the reservoir and allocates pressure contribution to temperature effect in the reservoir by assuming that the hydrocarbon reservoir is in effect in contact with a geothermal reservoir. Relationship between temperature and pressure in the reservoir was formulated and pressure contribution was allocated to temperature effect in the reservoir by assuming that the hydrocarbon reservoir is in effect in contact with a geothermal reservoir.

The results show that there exist a polynomial relationship between pressure and temperature in the reservoir. The higher the reservoir pressure the lower the in situ oil density and ultimately lower geothermal pressure contribution. The geothermal pressure contribution in reservoir pressure decreases as the traverse length (pay zone thickness) increases, its effect is negligible above 40 feet pay zone thickness. There exists polynomial relationship of degree six (6) between pay zone thickness and geothermal pressure contribution.
\end{abstract}

Keywords: Geothermal energy; Reservoir pressure; Geothermal gradient and thermal conductivity

\section{Nomenclature}

$$
\begin{aligned}
& \%=\text { percent } \\
& { }^{\circ} \mathrm{C}=\text { Degree centigrade } \\
& \mathrm{A}=\text { Geothermal contact Area, } \mathrm{ft}^{2} \\
& \mathrm{Ft} .=\text { Feet } \\
& \mathrm{H}=\text { Traverse length/ pay zone thickness, } \mathrm{ft} . \\
& \mathrm{Ib}=\text { Pounds } \\
& \mathrm{K}=\text { Total Thermal Conductivity, Btu/hr-ft.-of } \\
& \mathrm{KO}=\text { Thermal conductivity of oil, Btu/hr-ft.-of } \\
& \mathrm{KS}=\text { Thermal conductivity for a sandstone reservoir, Btu-in/hr- } \mathrm{ft}^{2} .{ }^{-}{ }^{\circ} \mathrm{f} \\
& \mathrm{Kw}=\text { Thermal conductivity of water, Btu-in/hr- } \mathrm{ft}^{2} \text {.-of } \\
& \mathrm{L}=\text { Heat traverse length, } \mathrm{ft} . \\
& \mathrm{m}=\text { Meter } \\
& { }^{\circ} \mathrm{F}=\text { Degree Fahrenheit } \\
& \mathrm{P}=\text { Pressure, psi } \\
& \text { PrG = Pressure contribution due to geothermal gradient, Psi } \\
& \mathrm{PSI}=\text { Pounds per square inch }
\end{aligned}
$$

$$
\begin{aligned}
& \text { So }=\text { Oil Saturation } \\
& \text { Sw }=\text { Water Saturation } \\
& \text { VR }=\text { Hydrocarbon pay zone volume, } \mathrm{ft}^{3} \\
& \Theta_{\mathrm{T}}=\text { Geothermal temperature, }{ }^{\circ} \mathrm{F} \\
& \rho \mathrm{h}=\text { Hydrocarbon density, } \mathrm{Ib} / \mathrm{ft}^{3} \\
& \phi=\text { Porosity, } \%
\end{aligned}
$$

\section{Introduction}

In the broadest sense, the geothermal energy can be defined as the natural heat content of the earth. The work of [1] (undated) outlined among other conditions, a heat source for the existence of a geothermal reservoir. The heat source can be a magmatic body $\left(>600^{\circ} \mathrm{C} / 1112^{\circ} \mathrm{F}\right)$ as well as the normal geothermal gradient of the earth as in the case of lowtemperature geothermal sources. The temperature of the earth increases

*Corresponding author: Olafuyi Olaleken, Assistant Professor, University of Benin, Benin City, Nigeria, Tel: +2348039351412; E-mail: mamuduabbas@yahoo. com

Received February 12, 2015; Accepted April 22, 2015; Published April 29, 2015

Citation: Olafuyi O, Ekeregbe MP (2015) Analyzing in situ Geothermal Energy Contribution to Hydrocarbon Reservoir Pressure. J Pet Environ Biotechnol 6: 224 doi:10.4172/2157-7463.1000224

Copyright: $\odot 2015$ Olafuyi $O$, et al. This is an open-access article distributed under the terms of the Creative Commons Attribution License, which permits unrestricted use, distribution, and reproduction in any medium, provided the original author and source are credited. 
with a normal geothermal gradient of $3^{\circ} \mathrm{C} / 100 \mathrm{~m}\left(37.4^{\circ} \mathrm{F} / 328.1 \mathrm{ft}\right.$.).It is therefore possible to reach a depth to obtain a temperature of $70-100^{\circ} \mathrm{C}$ $\left(158-212^{\circ} \mathrm{F}\right)$ with the existing drilling technology. Another factor for a geothermal reservoir to exist is the presence of a heat carrier which is mainly rain water seeping to the deeper section of the earth.

Wikipedia resource states that "The geothermal energy of the Earth's crust originates from the original formation of the planet (20\%) and from radioactive decay of minerals $(80 \%)$. The geothermal gradient, which is the difference in temperature between the core of the planet and its surface, drives a continuous conduction of thermal energy in the form of heat from the core to the surface". From the above assertion it can be stated that the temperature gradient across the earth is majorly from the earth core and the deeper the drilling goes the higher the temperature will become at that depth. Therefore the deepest reservoir will have the highest temperature in the same historical geological formation.

Temperature has a strong relationship with pressure in all fluid systems. It is a major factor for characterizing any reservoir system. The different reservoirs using the fluid phase behavior were defined from the pressure-temperature interactions. Under this phase behavior classification, the only factor that determines the fluid composition is the temperature, the reason the percent composition tends to zero as the temperature tends to two-phase maximum. So it is obvious that temperature has a major role in reservoir consideration.

Over the years the use of geothermal energy has had impact in the different field of human endeavors .It ranges from ancient time when geothermal energy from hot springs was used for bathing and heating; food-dehydration; medicinal purposes (ancient Romans) and mostly recently for power generation. Harnessing of the geothermal resource has led several authors and investigators to research into the mining of this resource.

Geothermal energy is a renewable energy source. Its heat flux is from the earth interior .If the resource temperature at $3281 \mathrm{ft}$ depth is higher than $392^{\circ} \mathrm{F}$ the geothermal resource is classified as high temperature field but low temperature field if less than $302^{\circ} \mathrm{F}$ as stated by [2-5]. This renewable energy if then proven to have any contribution to reservoir pressure might have constant effect on the hydrocarbon reservoir pressure which is non-depletable.

Several authors have studied different way of mining the geothermal energy content of the earth. One of the efforts of mining geothermal energy was the use of supercritical $\mathrm{CO}_{2}$ by [4-7] and the use of water in an induced geothermal reservoir.

According to [8], 24 countries utilized geothermal energy for power generation and 70 countries for geothermal heating as at 2012. These are the two dominant uses of geothermal energy. All researches and investigations have only dwelt on the use of geothermal energy through developing different mining processes, development of concepts for better exploitation [9]; as a renewable resource and risk mitigation [1018] among others. The area of its significance in hydrocarbon reservoir pressure contribution has not been researched for fluid production.

This paper presents a relationship between temperature and pressure in the reservoir and allocates pressure contribution to temperature effect in the reservoir by assuming that the hydrocarbon reservoir is in effect in contact with a geothermal reservoir. The geothermal reservoir in this context is the geothermal energy content in the reservoir formation and non-hydrocarbon fluid in contact with the reservoir.

\section{Methodology}

The oil and gas reservoir in contact by convection or conduction with a geothermal reservoir will have slightly the same geothermal temperature. With the fluid system being trapped, the hydrocarbongeothermal reservoir system behaves as a pressure cooker whose pressure will depend on

1. The geothermal temperature, $\Theta_{\mathrm{T}}$

2. Fluid properties (density, $\rho_{\mathrm{h}}$ )

3.The geothermal contact area, A

4. Total conductivity, $\mathrm{K}$

5. The hydrocarbon pay zone volume, $\mathrm{V}_{\mathrm{R}}$

6. Length of heat source contact to opposite end of reservoir, L

Mathematically,

$$
\mathrm{P}=\mathrm{f}\left(\Theta_{\mathrm{T}, \mathrm{h}} \rho_{\mathrm{h}} \mathrm{A}, \mathrm{K}, \mathrm{L}, \mathrm{V}_{\mathrm{R}}\right)
$$

It is also possible to posit that the geothermal temperature contributes to the kerogen generation during petroleum formation.

Because of the linear relation between temperature and pressure, the temperature gradient has a lot of effect on the reservoir pressure. The effect depends on the fluid and reservoir rock properties.

Applying the Buckingham [19] Pi theorem to (1) gives the relationship for pressure contribution to reservoir pressure due to geothermal effect as

$$
P_{r G}=\frac{A}{L^{2}} \frac{\sqrt[3]{\theta_{T}^{2} \rho_{h} k^{2}}}{\sqrt[9]{V_{R}^{2}}}
$$

The Pressure contribution due to geothermal gradient tends to maximum when the $\mathrm{A} / \mathrm{L}^{2}$ tends to unity in an edge water drive reservoir as shown in Figure 1. But in a bottom-water drive reservoir it is greatest with pay zone thickness at its least value.This seems the most influential element in geothermal pressure in the reservoir. If the geothermal heat carrier is the aquifer surrounding the reservoir as depicted in Figure 1 , then the Pressure contribution depends on the type of aquifer. For a bottom water aquifer with an infinite extent, $\mathrm{A} / \mathrm{L}^{2}$ can be greater or equal to unity. For edge water aquifer $\mathrm{A} / \mathrm{L}^{2}$ is less than unity.

For a special case of a reservoir edged with an active aquifer, assuming that the heat traverse length, $\mathrm{L}$ is equal to the diameter of the drainage area of the reservoir (for cyclic bounded reservoir); the ratio:

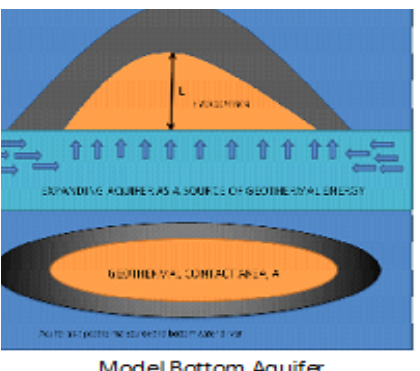

Model Bottom Aquife

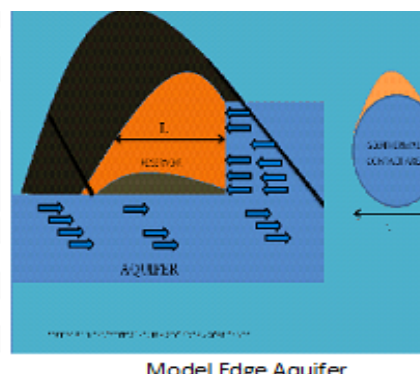

Model Edge Aquife

Figure 1: Geothermal Reservoir Model. 
Citation: Olafuyi O, Ekeregbe MP (2015) Analyzing in situ Geothermal EnergyContribution to Hydrocarbon Reservoir Pressure. J Pet Environ Biotechnol 6: 224. doi:10.4172/2157-7463.1000224

Page 3 of 6

$$
\frac{A}{L^{2}}=0.785398
$$

Therefore the pressure contribution for this special case is

$$
P_{r G}=0.785398 \frac{\sqrt[3]{\theta_{T}^{2} \rho_{h} k^{2}}}{\sqrt[9]{V_{R}^{2}}}
$$

General equation in field unit

$$
P_{r G}=1.879 \times 10^{-4} A \frac{\sqrt[3]{\theta_{T}^{2} \rho_{h} k^{2}}}{L^{2} \sqrt[9]{V_{R}^{2}}}
$$

Where

$$
\begin{aligned}
& P_{r G} \text { is in PSI } \\
& \rho_{h} \text { is in } \mathrm{Ib} / \mathrm{ft}^{3}
\end{aligned}
$$

$\mathrm{K}$ is in Btu-in/ $/ \mathrm{ft}^{2}-^{\circ} \mathrm{F}$ per 1 hour

$A$ is in $\mathrm{ft}^{2}$

$\mathrm{L}$ is in $\mathrm{ft}$

$\mathrm{V}$ is in $\mathrm{ft}^{3}$

$\Theta_{\mathrm{T}}$ is in ${ }^{\circ} \mathrm{F}$

$[20,21]$ in an experimentation also determined thermal conductivity for

Water $=0.609 \mathrm{w} / \mathrm{m} \mathrm{k}\left(4.22 \mathrm{Btu}-\mathrm{in} / \mathrm{ft}^{2}-\mathrm{hr}-{ }^{\circ} \mathrm{f}\right)$

The thermal conductivity of crude oil can be approximated using the correlation:

$$
K=\frac{1.62}{A P I}[1-0.00003(t-32)]
$$

Where $\mathrm{K}$ is in Btu/hr- $\mathrm{ft} .{ }^{\circ} \mathrm{f}$

$t$ is in ${ }^{\circ} \mathrm{f}$

Several works have been done to estimate the total thermal conductivity of the reservoir. Among them are the mixing law models, the empirical models and theoretical models. One of the best among these models is the Maxwell model:

$$
K=K_{f}\left[\frac{\left[2 \varnothing K_{f}+(3-2 \varnothing) K_{S}\right]}{(3-\varnothing) K_{f}+\varnothing K_{S}}\right]
$$

A modification to the above to account for water and oil in a water

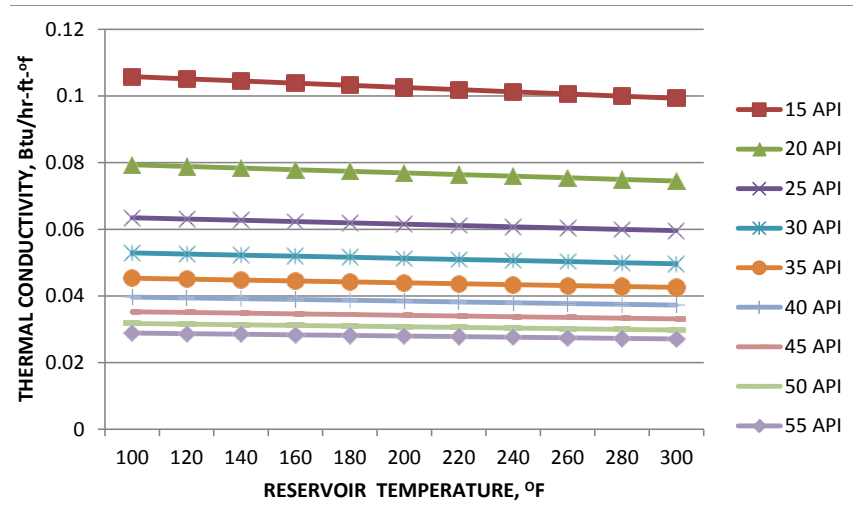

Figure 2: Crude Oil Thermal Conductivity Variation with Temperature. drive reservoir can be stated as:

$$
\mathrm{K}_{\mathrm{f}}=\mathrm{K}_{\mathrm{O}} \mathrm{S}_{\mathrm{O}}+\mathrm{K}_{\mathrm{w}} \mathrm{S}_{\mathrm{w}}
$$

A graphical representation of equation 6 for different reservoir temperature and crude oil gravity is shown in Figure 2. For different fluid saturations, combining (6) and (8) is graphically represented in Figure 3.

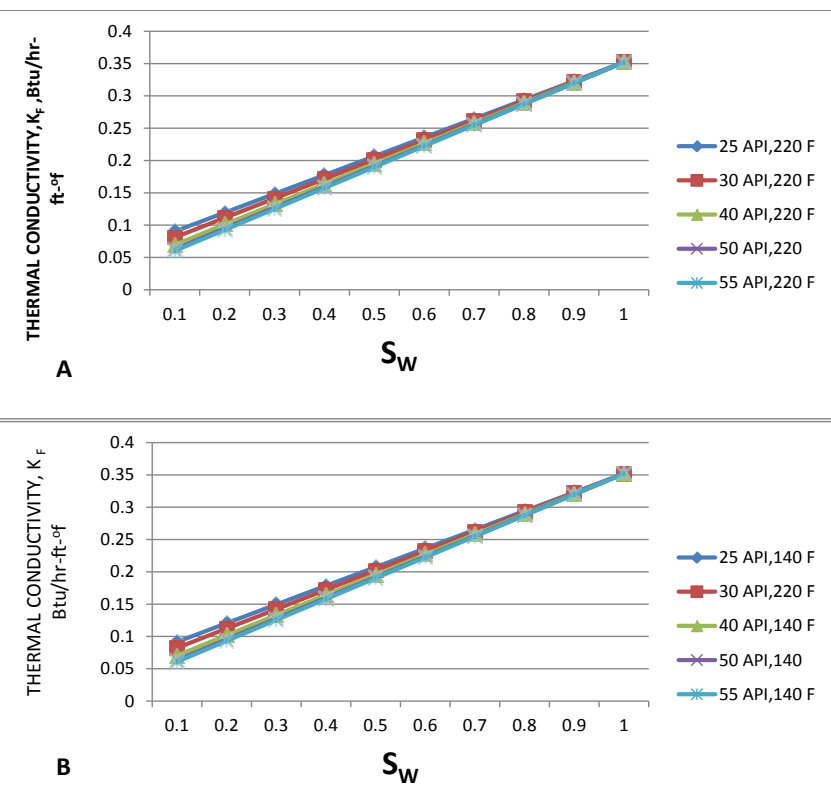

Figure 3: Crude Oil Thermal Conductivity Variation with Temperature and Saturation.

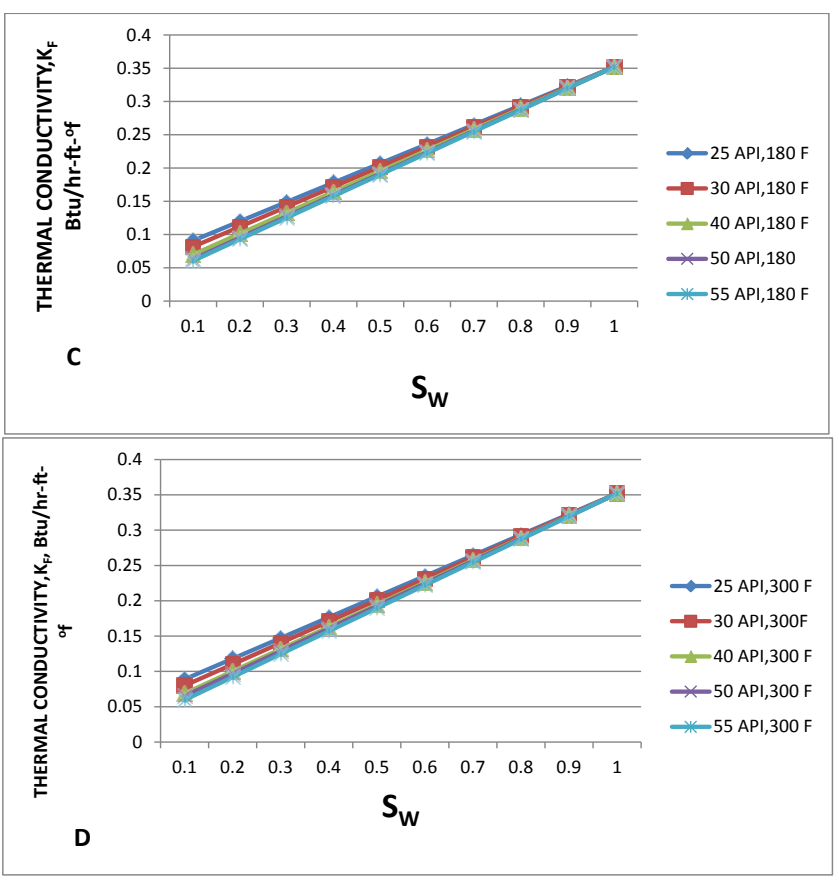

Figure 4: Crude Oil Thermal Conductivity Variation with Temperature and Saturation. 


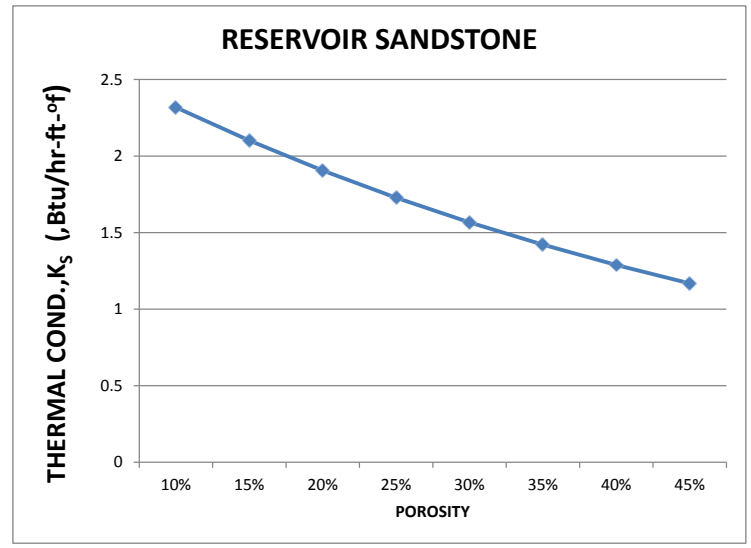

Figure 5: Formation Thermal Conductivity Variation with Porosity.

An approximate value can be employed using the correlation stated in the work of Griffith et al. to estimate the thermal conductivityporosity correlation of reservoir sandstone:

$$
\mathrm{K}_{\mathrm{S}}=0.69^{\phi}\left(4.88^{(1-\phi)}\right),(\mathrm{W} / \mathrm{mk})
$$

Graphically representing (9) in Btu-in/ $\mathrm{ft}^{2}{ }^{\circ} \mathrm{F}$ per 1 hour is shown in chart Figure 4 for easy estimation of reservoir sandstone thermal conductivity.

\section{Results and Discussion}

The reservoir is a complex system which does not behave as an empty vessel filled with hydrocarbon. The pressure-temperature interaction in a vessel fully occupied by hydrocarbon deviates far from behavior in a reservoir. The interaction of granular pores; formation type and fluid saturation among others make temperature-pressure interaction in the reservoir a non-linear relationship. Under the mathematical formulation of this paper, the relationship among these reservoir parameters is polynomial, and of degree three (3). This is as shown in Figure 8. This figure depicts the Temperature-Pressure relationship as shown in equation (1.2) by keeping other parameters constant. This was done considering different reservoir pressure regimes and see the effect of what the Temperature contribution to pressure would be. The higher the temperature the higher the Geothermal contributed pressure as shown in Figure 8 below. But in these charts the pay zone thickness (Traverse length) shows a strong dominance in the geothermal pressure contributed.

$$
P_{r G 20}>\left[\frac{20}{2}\right]^{2} P_{r G 40}
$$
of $20 \mathrm{ft}$

Where $\mathrm{P}_{\mathrm{rG} 20}$ is the pressure due to traverse length/pay zone thickness $40 \mathrm{ft}$.

$\mathrm{P}_{\mathrm{rG} 40}$ is the pressure due to traverse length/pay zone thickness of

Geothermal pressure also varies with the dominant parameters as shown in Figures 5-9. When these parameters are held constant the variation in pressure is higher in traverse length variation than any other parameters shown in these figures. The Figure 9, display a polynomial of degree six (6) relating the traverse length with the geothermal pressure contribution.

\section{Conclusion}

There exist a polynomial relationship between pressure and
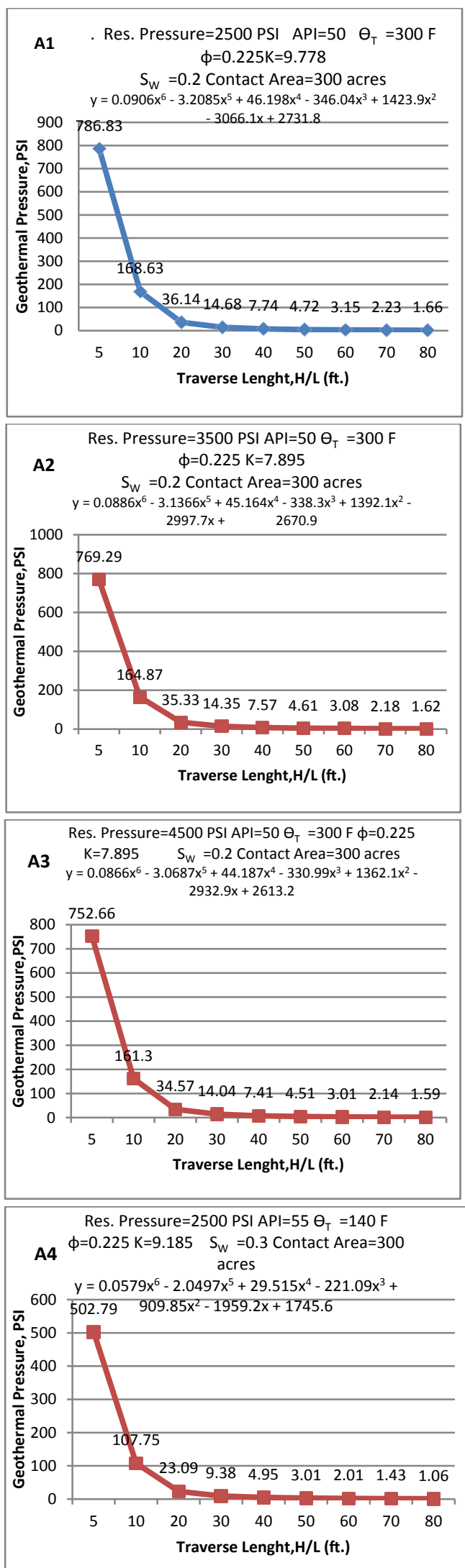

Figure 6: Geothermal Contribution due to varying Parameters. 
Citation: Olafuyi O, Ekeregbe MP (2015) Analyzing in situ Geothermal EnergyContribution to Hydrocarbon Reservoir Pressure. J Pet Environ Biotechnol 6: 224. doi:10.4172/2157-7463.1000224
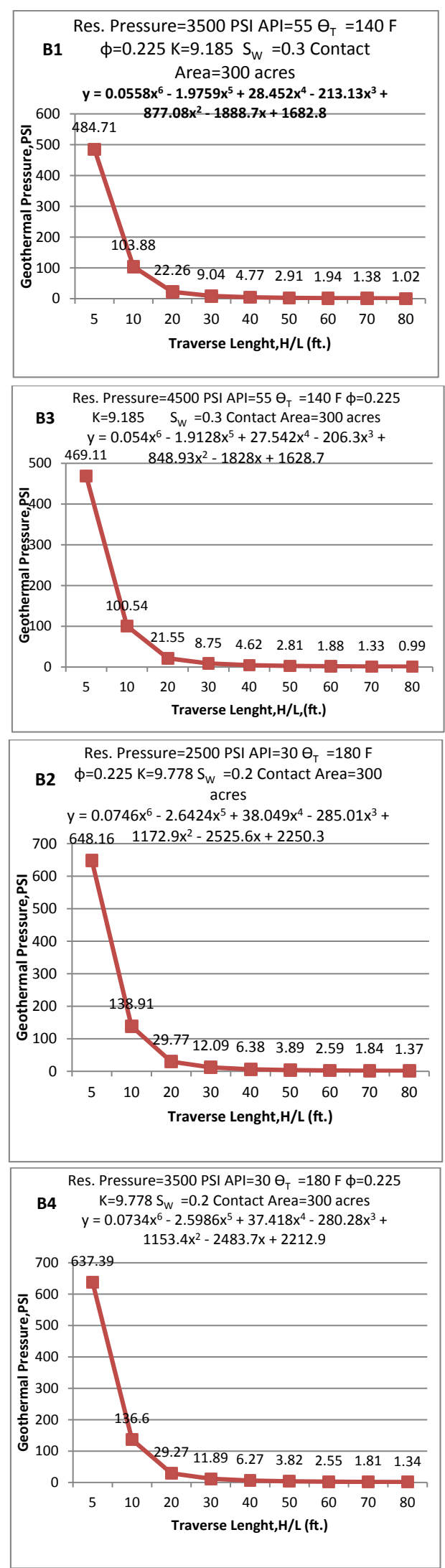

Figure 7: Geothermal Contribution due to varying Parameters.

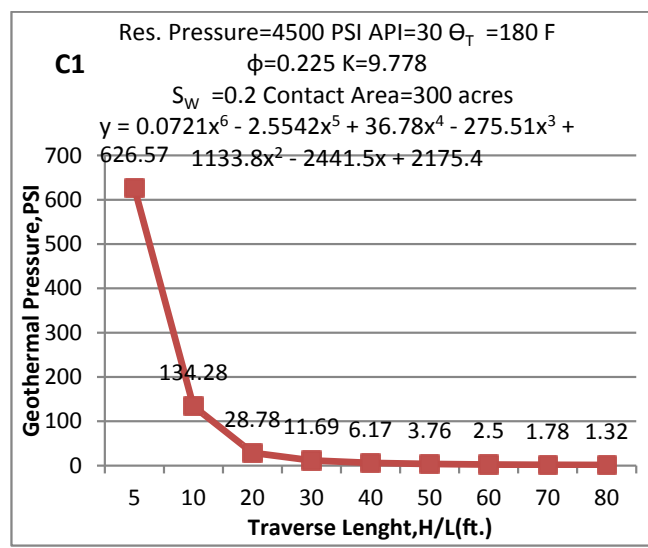

Res. Pressure $=2500 \mathrm{PSI}$ API $=40 \Theta_{\mathrm{T}}=180 \mathrm{~F} \phi=0.3$

C3 $\mathrm{K}=6.266 \mathrm{~S}_{\mathrm{W}}=0.2$ Contact Area $=300$ acres $y=0.0583 x^{6}-2.0644 x^{5}+29.728 x^{4}-222.69 x^{3}+$

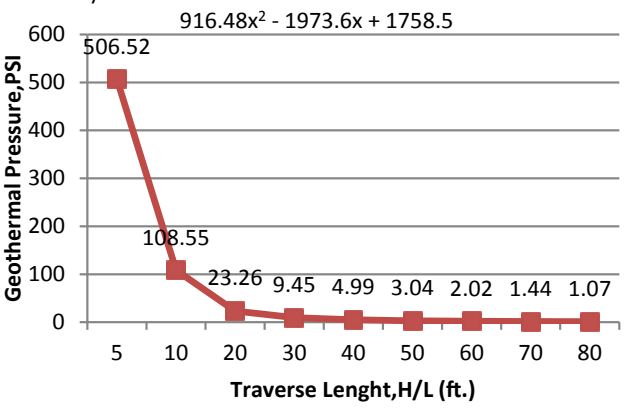

Res. Pressure $=4500$ PSI API $=40 \theta_{\mathrm{T}}=180 \mathrm{~F}$

C2 $\phi=0.3 \mathrm{~K}=6.266 \mathrm{~S}_{\mathrm{W}}=0.2$ Contact Area $=300$ acres

$y=0.0557 x^{6}-1.9733 x^{5}+28.415 x^{4}-212.84 x^{3}+$

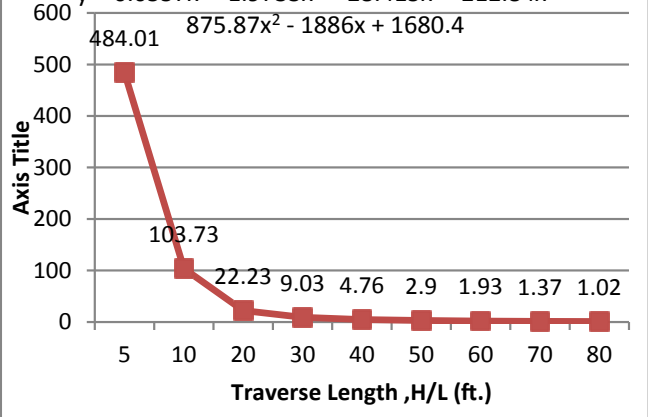

C4 Res. Pressure $=3500$ PSI API $=40 \Theta_{T}=180 \mathrm{~F} \phi=0.3$

$\mathrm{K}=6.266 \mathrm{~S}_{\mathrm{W}}=0.2$ Contact Area $=300$ acres

$y=0.057 x^{6}-2.0186 x^{5}+29.065 x^{4}-217.71 x^{3}+$ $895.88 x^{2}-1929.1 x+1718.8$

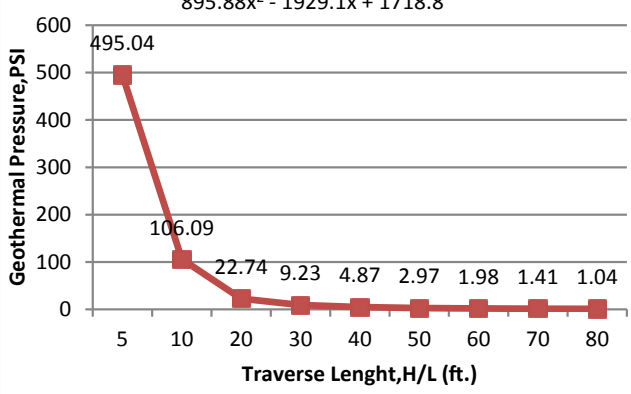

Figure 8: Geothermal Contribution due to varying Parameters. 
Citation: Olafuyi O, Ekeregbe MP (2015) Analyzing in situ Geothermal EnergyContribution to Hydrocarbon Reservoir Pressure. J Pet Environ Biotechnol 6: 224. doi:10.4172/2157-7463.1000224

Page 6 of 6

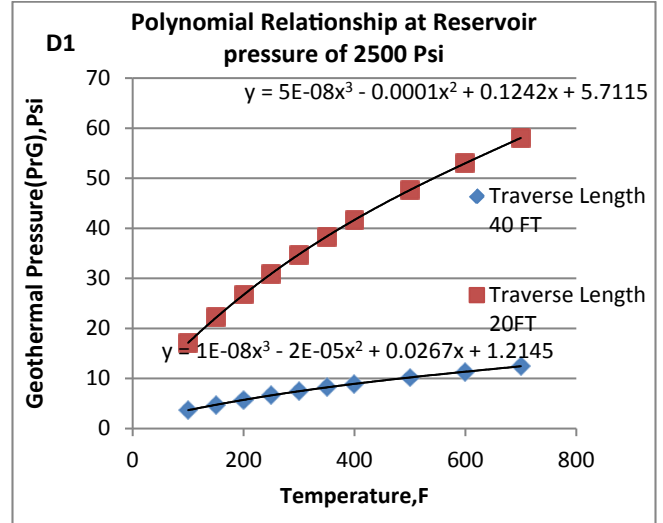

D3 Polynomial Relationship at Reservoir pressure of

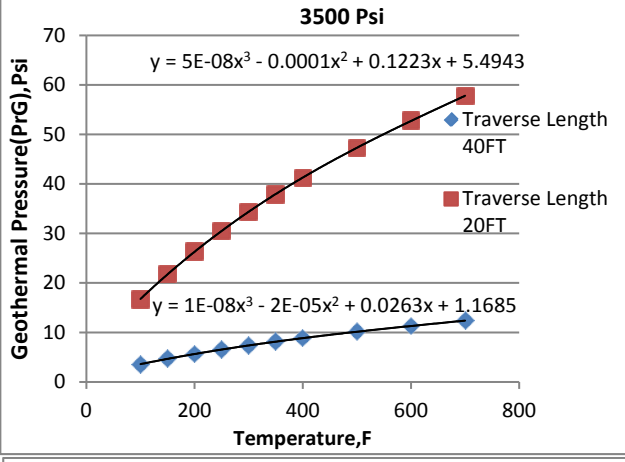

D2 Polynomial Relationship at Reservoir

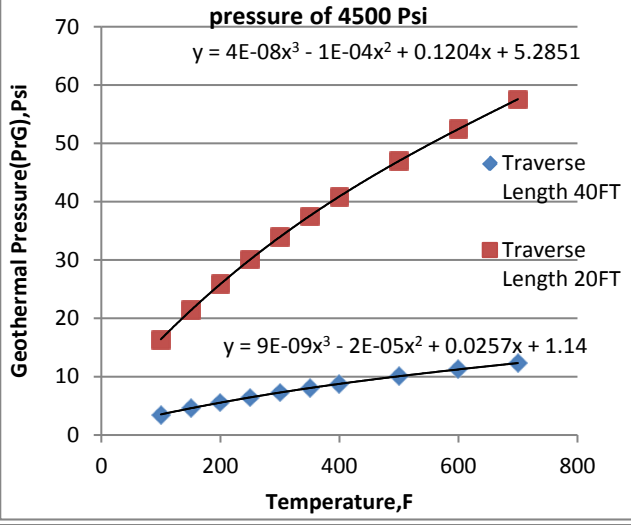

Polynomial Relationship at Reservoir pressure of

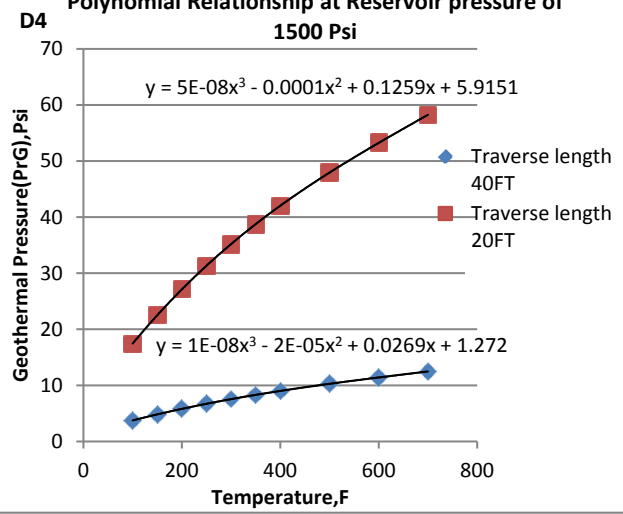

Figure 9: Relationship between Reservoir Temperature and Geothermal Pressure contribution. temperature in the reservoir. The higher the reservoir pressure the lower the in situ oil density and ultimately lower geothermal pressure contribution. The geothermal pressure contribution in reservoir pressure decreases as the traverse length (pay zone thickness) increases. Its effect is negligible above 40 feet pay zone thickness. There exists polynomial relationship of degree six (6) between pay zone thickness and geothermal pressure contribution.

\section{References}

1. Mahmut $P$ (undated) Geothermal Reservoir Engineering. Petroleum and Natural Gas. Department of Middle East Technical University

2. Allenkirch RA (undated) College of Engineering, Mississippi State University Mississippi, USA.

3. Bear J (Ed) (1972) Dynamics of Fluid in porous media, 444-449.

4. Carter RD, Tracy GW (1960) An Improved Method for Calculating Water Influx. Trans. AIME 219: 415

5. Coats KH (1970) Mathematical Methods for Reservoir Simulation. Presented by the College of Engineering, University of Texas at Austin: 8-12.

6. Craft BC, Hawkins M, Ronald ET (1991) Applied Petroleum Reservoir Engineering (2ndedn), Prentice Hall, USA.

7. Fetkovich MJ (1971) A Simplified Approach to Water Influx Calculations-Finite Aquifer Systems. J Pet Techno 23: 814-828.

8. Geothermal Energy Association Report (2014) Best Practices for Geothermal Power Risk Reduction Workshop Follow-Up Manual.

9. Gioia F, Teodoriu C (2008) Oil and Gas expertise for Geothermal Exploitation: the Need for Technology Transfer. Society of Petroleum Engineers.

10. Watson S. How Geothermal Energy Works.

11. White FM (2014) The Buckingham PI Theorem/Method. In: Fluid Mechanics/ Dimensional Analysis.

12. Harald A (2006) Fluid properties.

13. Prisciliano F, Bruce JB, Derrick G, Michael M, Josh D (1934) Capillary Pressure Measurements in Petroleum Reservoir with MRI (OTC 19234), MRI Centre University of New Brunswick, Houston, Texas, USA

14. Schilthuis RJ (1936) Active Oil and Reservoir Energy. Trans., AIME 118: 33.

15. Schon J (2011) Physical properties of rocks: A work book. Handbook of Petroleum Exploration and Production. Elsevier Science Publishing Company Inc. New York, NY 10010, USA.

16. Siegesmund S, Snethlage R (2011) Stone in Architecture, Properties and Durability. Springer, London

17. Somerton WH (1992) Thermal Properties and Temperature related Behavior of Rock/Fluid System. Elsevier Science Publishing Company Inc. New York, NY 10010, USA

18. Turcotte DL, Schubert G (2002) Geodynamics (2ndedn). UK Cambridge University Press: 136-137.

19. Van Everdingen AF, Hurst W (1949) The Application of the Laplace Transformation to Flow Problems in Reservoirs. Trans., AIME

20. Wang Y, Bicheng Y, John K (2013) Compositional Modeling of Tight Oil using Dynamic Nanopore Properties. SPE 166267.SPE Texas A\&M University, USA

21. Williams CL, Gary JPBS (1996) Standard Handbook of Petroleum and Natural Gas Engineering 2. Gulf Publishing Company, Houston, Texas, USA. 